\title{
Formação do pesquisador: resultados de cursos de pós-graduação em educação ${ }^{1}$
}

\author{
Maria Benedita Lima Pardo ${ }^{2}$ \\ Universidade Federal de Sergipe, Aracaju-SE, Brasil \\ Neucideia Aparecida Silva Colnago
}

\begin{abstract}
Resumo: O objetivo desta pesquisa foi analisar como alunos de dois cursos de mestrado na área de Educação avaliam sua formação em pesquisa na graduação e na pós-graduação (cursos A e B). Foram aplicados questionários a 28 alunos de mestrado do segundo ano de ambos os cursos. Os dados foram submetidos à análise de conteúdo. Os resultados indicaram que os alunos do curso B se adequaram melhor ao perfil esperado pelas agências de fomento, assim como sua condição de trabalho no mestrado. Além disso, um maior número deles havia realizado iniciação científica. Em relação à avaliação das etapas de aprendizagem de pesquisa os alunos de ambas as universidades optaram, com maior frequência, pelas categorias: Bom, Muito bom e Excelente. Em relação às etapas de execução da pesquisa sobressaiu o grande número de respostas "não trabalhou" pelos alunos do curso A. Tais resultados podem ser utilizados para aperfeiçoamento do processo de formação do pesquisador.
\end{abstract}

Palavras-chave: pesquisa científica, pós-graduação, aprendizagem.

\section{Research capacity: results of graduates course in education}

\begin{abstract}
This research aims to analyze how the students from two master's science Education Courses from two public Universities (courses A e B) evaluated their research capacity on under graduation and master's science courses. The questioners were applied to 28 students on the second years from both of courses. The data were submitted to the content analysis. The results showed that the profile of students from the course B was similar to the one expected by support research agencies as well their work condition on master's science course. Most of them also had scientific experience during under graduation course. Students in both Education Courses evaluated positively their scientific capacity (good, very good and excellent). On the phases of development of the scientific research some students from the course A had answered "not worked" in several phases. Those results could be utilized to improve de the research capacity process.
\end{abstract}

Keywords: scientific research, postgraduated training, learning.

\section{La formación del investigador: resultados de programas de postgrado en educación}

\begin{abstract}
Resumen: Con el objetivo de evaluar la formación en investigación durante la universidad y los post-grados de alumnos de dos cursos de Maestría en Educación (cursos A y B) fueron entrevistados 28 alumnos del segundo año de ambos cursos y los datos fueron analizados considerando el contenido. Los resultados indican que los alumnos del curso B se adaptan mejor al perfil deseado por las agencias patrocinadoras y también a los trabajos de Maestría. Vale resaltar que la mayoría de los alumnos ya había hecho la iniciación cientifica antes. Los alumnos de ambas universidades optaron con mayor frecuencia, por la evaluación de las etapas de aprendizaje de la investigación utilizando las categorías Bueno, Muy Bueno y Excelente. En relación a las etapas de ejecución de la investigación sobresalió el número de respuestas "no ha trabajado" por los alumnos del curso A. Estos resultados pueden ser utilizados para mejorar el proceso de formación del investigador.
\end{abstract}

Palabras clave: investigación científica, post graduación, aprendizaje.

A pesquisa é uma das atividades intrínsecas e essenciais à instituição universitária, ao lado do ensino e da extensão (Paiva, 2001). Dentre as importantes missões da instituição superior, uma delas é difundir o conhecimento acumulado através do ensino. Outra missão, igualmente relevante, é a produção de novos conhecimentos, o que se faz pela pesquisa. Segundo Fávero (1998), a universidade, por suas próprias funções, deve se constituir em um espaço de investigação científica e

\footnotetext{
${ }^{1}$ Este texto foi revisado seguindo o Acordo Ortográfico da Língua Portuguesa (1990), em vigor a partir de $1^{\circ}$ de janeiro de 2009 . Colaboraram com a coleta e análise dos dados as alunas do curso de Psicologia da Universidade Federal de Sergipe: Christianne Rocha Gomes e Ana Almeida Costa. Financiamento: PIBIC/CNPq/UFS.

${ }^{2}$ Endereço para correspondência:

Maria Benedita Lima Pardo. Rua Vila Cristina, 68, apto 301. CEP

49.015-000. Aracaju-SE, Brasil.E-mail: pardombl@hotmail.com
}

de produção de conhecimento. Essa produção deve buscar responder às necessidades e ter, como preocupação, constituir-se na expressão do real, expressão que deve ser compreendida como característica do procedimento científico.

O desenvolvimento de pesquisas permite a geração de novos conhecimentos e a elaboração de tecnologias cientificamente fundamentadas que poderão ser aplicadas à resolução de problemas nas diversas áreas de atuação do homem. Desse modo, ao incentivar o desenvolvimento de pesquisas a universidade estará cumprindo aspectos importantes de suas funções sociais (Pardo, 2004a).

Consta na Lei de Diretrizes e Bases da Educação Nacional (LDBEN) (Lei No. 9.394, 1996), promulgada no final de 1996, que as instituições de ensino superior devem ter um mínimo de um terço de mestres ou doutores em seu corpo docente para que possam ser credenciadas. Tal critério evidencia o reconhecimento da importância da 
pesquisa. Além disso, a LDBEN determina que as universidades tenham como característica o desenvolvimento de pesquisa institucionalizada (Velloso, 2003).

Nas instituições de ensino superior, a pesquisa pode ser realizada tanto na graduação como na pós-graduação. Assim a formação do pesquisador poderia e deveria estar se iniciando no curso de graduação. Alguns autores têm se dedicado a esse assunto e defendem a iniciação da formação em pesquisa no decorrer da graduação (Dal Ri, 1996; Leite, 1996; Machado, 1996; Simão, 1996). Vale destacar que nesse processo a formação deverá estar sob a orientação de professores-pesquisadores. Uma vez que o aluno tenha participado do processo de pesquisa durante a graduação e se interessado em ingressar no mestrado estaria levando consigo experiência teórica e prática que o ajudaria no desenvolvimento de suas atividades na pós-graduação.

Esta pesquisa foi desenvolvida a partir de considerações sobre a atual importância do tema formação do pesquisador e a ênfase de diversos autores à formação em pesquisa. Busca introduzir um enfoque pouco abordado na literatura pesquisada, qual seja, a opinião do próprio mestrando sobre sua formação. Visa, ainda, a obtenção de indicadores que possam ser utilizados, ao lado de outros adotados pelas agências de fomento, para a melhoria do processo de formação do pesquisador.

A pesquisa faz parte de um projeto mais amplo inicialmente desenvolvido na universidade onde funciona o curso A, situada na região Nordeste, que se ampliou para outras instituições de ensino superior, visando obter dados comparativos de cursos pertencentes à mesma área de conhecimento e localizados em diferentes regiões do país. Neste artigo são apresentados os resultados obtidos com alunos dos cursos de mestrado na área de Educação da universidade onde funciona o curso A e de outra universidade situada na região Sudeste, onde funciona o curso B. Ambas se inserem no sistema federal de ensino superior. São analisadas características da formação em pesquisa desses mestrandos durante a graduação, bem como no decorrer do curso de pósgraduação. Além disso, são apresentadas as opiniões desses participantes sobre melhorias que poderiam ser introduzidas nos cursos visando o aperfeiçoamento do processo de formação do pesquisador.

Segundo informações obtidas junto à Pró-reitoria de Pós-graduação, o curso A tem área de concentração em História, Sociedade e Educação/Novas Tecnologias, Educação e Trabalho. Iniciou suas atividades em 1985, mas teve dificuldades para obter a aprovação pela Coordenação de Aperfeiçoamento de Pessoal de Nível Superior (CAPES). Com o apoio da Pró-reitoria foi reformulada sua proposta, além da realização de melhorias em suas condições de funcionamento, obtendo aprovação em 2002. Posteriormente suas avaliações foram melhorando e recentemente obteve autorização para o funcionamento do curso de Doutorado. Tratase, portanto, de um programa de pós-graduação em processo de consolidação.
O curso B iniciou suas atividades em 1978, passou por várias reformulações curriculares e alteração do nome e da área de concentração para "Educação do indivíduo especial", buscando maior abrangência. Vinte e um anos após a abertura do mestrado, em 1999, o Programa obteve autorização para abertura do Doutorado. Atualmente é um Programa consolidado, tendo formado mais de 300 mestres e 11 doutores.

\section{A universidade e a formação em pesquisa}

A presença da pesquisa na universidade e sua relação com o ensino são questões que têm acompanhado a trajetória da universidade brasileira desde a sua criação, na década de 1920.

A universidade possui algumas características e funções que a diferenciam de outras instituições de ensino de terceiro grau. Segundo Santos (2005), ela possui algumas características específicas: permite aos estudantes e aos professores acesso aos diversos campos da cultura e da ciência; possui um amplo espectro denominado "extensão de serviços à comunidade", sendo o ensino e a pesquisa seus serviços centrais; e desenvolve atividades de pós-graduação com o ensino da pesquisa no mestrado, doutorado e em cursos de especialização.

Essa mesma autora relaciona três modelos que foram se constituindo ao longo da história das universidades modernas. Segundo ela, hoje, a universidade é um pouco desses três modelos: uma espécie de agente prestador de serviços, o qual costuma incluir, também, atividades de ensino e treinamento menos formalizados; um lugar privilegiado de preparação para o exercício de profissões, cada vez mais regulamentadas; e um lugar da pesquisa (básica e aplicada), no que se refere à sua prática e ensino, pela qual se produz novo conhecimento. Esse trabalho se prenderá à terceira característica apontada, lugar de desenvolvimento de atividades de pós-graduação, e ao terceiro modelo citado, lugar de pesquisa.

Velloso (2003) relata que, no Brasil, a pós-graduação foi regulamentada em meados dos anos de 1960, quando contava com 38 cursos no país, sendo 11 de doutorado e o restante de mestrado. A partir desse momento, passou por grande expansão, consolidação e ampliação de suas áreas de conhecimento, principalmente a partir da década de 1990. Neves (2002) destaca que a educação superior no Brasil abarca, hoje, um sistema complexo e diversificado de instituições públicas e privadas com diferentes tipos de cursos e programas, incluindo vários níveis de ensino desde a graduação até a pós-graduação lato sensu e stricto sensu. Nessa pesquisa, destacaremos apenas a pós-graduação stricto sensu, integrada pelo mestrado e doutorado.

Juntamente ao processo de ampliação da formação em pesquisa, é necessário o desenvolvimento de sistemáticas que viabilizem a avaliação dos produtos gerados. Tal processo de avaliação é assumido pela CAPES e tem produzido indicadores importantes quanto aos aspectos quantitativos da 
formação de pesquisadores nos níveis de mestrado e doutorado. Essas avaliações fornecem uma visão panorâmica do funcionamento dos cursos de pós-graduação, mas não viabilizam uma análise mais específica sobre o que ocorre com o pós-graduando no decorrer de seu processo de formação como pesquisador (Pardo, 2004b).

A formação de pesquisadores também tem sido um tema frequente nas discussões relativas à melhoria da qualidade de ensino nas universidades e, há muitos anos, vem merecendo incentivo por parte das agências de fomento sob forma de concessões de bolsas de estudo. A expansão do sistema nacional de pós-graduação e o consequente crescimento do contingente de novos mestres e doutores derivam, em grande parte, da existência de programas mantidos pelas agências de fomento nacionais e estaduais visando o fortalecimento dos cursos existentes e a manutenção dos programas de bolsas de estudos (Velloso, 2003).

A pós-graduação tem contribuído consideravelmente para a formação de recursos humanos qualificados e para o desenvolvimento científico do país. Além disso, por meio da pesquisa, contribui para a consolidação da base científica nacional, uma das principais condições que possibilitam o aperfeiçoamento do sistema educacional como um todo (Olive, 2002).

Essas duas funções da pós-graduação mostram-se evidentes pelo fato de que, nos últimos quinze anos, o Brasil tem sido o país com a segunda maior taxa de crescimento da produção científica, medida pelo número de artigos científicos publicados nas principais revistas especializadas internacionais. Deve-se também ressaltar que, atualmente, o Brasil vem formando cerca de seis mil doutores por ano (Perez, 2002). Esse mesmo autor destaca o impacto transformador no ambiente cultural do país causado pelas pesquisas desenvolvidas no curso de pós-graduação, na medida em que possibilitam ampliar o conhecimento dos processos e movimentos sociais e maior aperfeiçoamento da capacidade de intervenção da sociedade no sentido da solução de seus problemas.

Segundo Gomes (2004) algumas características são necessárias para o sucesso do curso de pós-graduação, tais como, rigor na formação de pesquisadores e a pesquisa como atividade fundamental que propicia reprodução, análise crítica e geração de conhecimento. Assim, é necessário haver maior intercâmbio entre a graduação e a pós-graduação, visando melhoria na qualidade de ensino da primeira.

Para Missiagia (entrevista concedida à TV Educativa do Rio de Janeiro em 30/12/2002) a experiência em pesquisa na graduação é importante devido à educação possibilitada pela mesma. A vivência da pesquisa desde a graduação, é relevante na medida em que se constitui em forma de socialização e construção de autonomia dos sujeitos envolvidos, garantindo-lhes um domínio qualitativo do instrumental da ciência e preparação para intervenções transformadoras nas realidades em que se inserem. Para o referido autor, os pesquisadores participam das decisões sobre o encaminhamento da pesquisa, necessitam fazer opções próprias sobre formas de encontrar respostas a questionamentos, envolvem-se em produções individuais e precisam saber defender seus pontos de vista, tornando-se mais autônomos. O verdadeiro produto da educação pela pesquisa é sua qualidade política transformadora, pois a experiência em pesquisa promove sujeitos autônomos e capazes de tomarem decisões próprias, possibilitando a transformação das realidades em que estão inseridos.

Segundo Fávero (1998) é imprescindível que a pesquisa desenvolvida na graduação tenha suporte teórico-metodológico que possibilite ao estudante delinear um problema e ser capaz de problematizá-lo, juntamente com um pesquisador mais experiente. É preciso que aquele que se inicia no trabalho de pesquisa tenha oportunidade de discutir os fundamentos do tema em estudo, o valor e os limites dos métodos que utiliza, as possibilidades explicativas das teorias e dos procedimentos adotados, as leis que descobre e a lógica que utiliza. Para isso é de grande relevância o programa desenvolvido pelo CNPq, entre outras agências de fomento, buscando iniciar estudantes de graduação na investigação científica e contribuir para a institucionalização da pesquisa nas universidades.

A presente pesquisa foi elaborada considerando a importância da investigação para a produção de conhecimentos sistematizados e para o desenvolvimento da sociedade. Busca também contribuir com sugestões para a melhoria de condições para o desenvolvimento dessa atividade. Seu objetivo foi o de levantar as percepções de mestrandos de dois cursos da área de Educação, cursos A e B, ingressos no ano de 2003, sobre sua experiência em pesquisa na graduação, a formação que vinham recebendo na pós-graduação e quais aspectos dessa necessitavam de aprimoramento.

\section{Método}

Esta pesquisa caracteriza-se como um estudo descritivo, pois tem como objetivo descrever as características de um determinado fenômeno (Gil, 1999). Segundo esse autor as pesquisas assim classificadas, além de levantarem as características do objeto de estudo podem ainda contribuir para a atuação prática ou intervenção.

\section{Participantes}

Participaram da pesquisa 10 alunos do curso A, representando $75 \%$ dos alunos ingressos em 2003. Os resultados desse grupo foram comparados aos de 18 alunos do curso B, representando $90 \%$ dos alunos ingressos no mesmo ano. A descrição dos participantes será apresentada mais detalhadamente na seção Resultados e Discussão.

\section{Instrumento}

Para a coleta de dados elaborou-se um questionário, contendo questões abertas e fechadas, composto por três 
dimensões: caracterização do participante, análise da experiência em pesquisa na graduação e análise da experiência no mestrado. Este instrumento foi submetido a um pré-teste anteriormente à coleta de dados definitiva.

\section{Procedimento}

\section{Coleta de dados}

Inicialmente o projeto foi apresentado aos coordenadores de ambos os cursos de mestrado, solicitando anuência para a aplicação do questionário. A seguir, foi feito contato com os alunos que estavam cursando o terceiro semestre do curso e a eles foram apresentados os objetivos da pesquisa, além de receberem um exemplar do questionário, esclarecendo-se nesse momento quaisquer dúvidas quanto ao seu preenchimento. O participante tinha prazo de uma semana para responder, findo o qual o pesquisador fazia novo contato para a devolução do material.

\section{Análise de dados}

As respostas às alternativas das questões fechadas foram tabuladas contando-se suas frequências e calculando-se as porcentagens de ocorrência. As respostas às questões abertas foram submetidas à análise de conteúdo (Bardin, 2004). Segundo essa autora tal método refere-se a um conjunto de técnicas "que utiliza procedimentos sistemáticos e objetivos de descrição do conteúdo das mensagens" (p. 33).

Para proceder a essa análise as respostas foram inicialmente relacionadas aos temas das questões e em seguida seu conteúdos foram agrupados em categorias de acordo com a similaridade de significado. Desse modo, as respostas poderiam apresentar mais de um conteúdo relacionado ao tema da questão. A seguir foram computadas as frequências de ocorrências em cada categoria. Os conteúdos incluídos em cada uma delas são ilustrados na seção de descrição dos resultados.

Os resultados de ambos os cursos são apresentados em gráficos e tabelas. Quando possível, também são comparados àqueles obtidos em pesquisa desenvolvida em cursos da área de Psicologia, uma vez que não foram encontrados estudos de cursos na área de Educação.

\section{Considerações éticas}

Este projeto de pesquisa recebeu parecer favorável do Comitê de Ética da Universidade Federal de Sergipe, em 06/03/2003, não sendo registrado número de protocolo, apenas datado. Os alunos que concordaram em participar assinaram o Termo de Consentimento Livre e Esclarecido.

\section{Resultados e Discussão}

\section{Caracterização dos participantes}

$\mathrm{Na}$ parte inicial do questionário, foram abordadas questões referentes à idade, sexo, à ocupação dos mestrandos, ao intervalo de tempo transcorrido entre o término do curso de graduação e início do mestrado, à possibilidade de terem cursado outra graduação ou curso de especialização e ao recebimento de bolsas de estudo no mestrado.

Com relação à idade dos participantes do curso $\mathrm{A}$, foi constatada uma variação de 26 a 50 anos. A média de idade deste grupo foi de 35 anos e quatro meses. Já a média de idade dos participantes do curso B foi de 27 anos e dois meses, havendo uma variação de 23 a 46 anos. Para Missiagia (entrevista concedida à TV Educativa do Rio de Janeiro em $30 / 12 / 2002$ ), a idade é um fator importante a ser considerado no treinamento de um futuro pesquisador, uma vez que iniciar o curso de mestrado mais cedo agiliza a formação e o início de sua produtividade em pesquisa.

Quanto ao sexo dos alunos participantes, o grupo de mestrandos do curso A era constituído por três homens e sete mulheres, enquanto o grupo do curso B era formado por três homens e 15 mulheres. Portanto, o sexo feminino predominou em ambos os grupos. Weber (2003) em estudo sobre a trajetória profissional de mestres e doutores formados em cursos de pós-graduação em Psicologia encontrou resultado semelhante. Em sua pesquisa mais de três quartos dos mestres e doutores formados pelos cursos pesquisados eram do sexo feminino.

A questão seguinte foi proposta a fim de verificar se os participantes tinham outra ocupação além do curso de pós-graduação. Dos mestrandos do curso A, apenas 10\% responderam que não possuíam outra ocupação e $90 \%$ deles responderam que sim, sendo que $40 \%$ destes trabalhavam em instituição privada e $60 \%$ em instituição pública. Vale destacar ainda que dois alunos (20\%) eram bolsistas sendo que um recebia bolsa CAPES e outro a recebia de outra instituição pública. Esse fato está parcialmente de acordo com a informação obtida junto ao coordenador do curso de que os alunos que recebem bolsa não devem ter nenhuma outra ocupação para que possam dedicar-se exclusivamente ao mestrado, pois um dos alunos com bolsa declarou não ter dedicação exclusiva ao curso de mestrado.

Com relação aos alunos do curso $\mathrm{B}$, seis mestrandos (33\%) responderam que tinham outra ocupação e doze (67\%) deles responderam que não. Quanto ao número de bolsas dos mestrandos, obteve-se como resultado que seis alunos não possuíam bolsa, enquanto doze a possuíam. Dos doze alunos, oito recebiam bolsa do $\mathrm{CNPq}$, três recebiam bolsa CAPES e um deles recebia bolsa da Fundação Estadual de Amparo à Pesquisa. Proporcionalmente, o grupo de alunos desse curso, apresentou maior número de bolsas $(67 \%$ de alunos bolsistas) que o grupo do curso B ( $20 \%$ de alunos bolsistas). Esses índices estão de acordo com a pesquisa de Velloso e Velho (2001), que encontraram menor distribuição de bolsas de estudo em cursos de mestrado da região nordeste.

Com relação ao curso em que se graduaram dos dez mestrandos do curso $\mathrm{A}$, somente dois deles não se graduaram na própria instituição e apenas um a cursou em universidade privada. Com relação aos mestrandos do curso B, 6 
mestrandos $(33 \%)$ graduaram-se na própria instituição, três deles (17\%) não responderam a essa questão e o restante estudou em diversas universidades. Quanto ao tipo de instituição em que cursaram a graduação, apenas quatro deles (22\%) a cursaram em instituição privada. Os $78 \%$ restantes cursaram em instituições públicas.

A média de tempo entre o término da graduação e o ingresso na pós-graduação, entre os alunos do mestrado do curso A foi de seis anos e quatro meses, maior que a obtida pelos alunos do curso B de três anos e sete meses. Esses resultados estão coerentes com o fato da maioria dos alunos do curso A (60\%) ter realizado curso de especialização, o que pode ter contribuído para a demora no ingresso para o mestrado. Já no curso B a maioria dos alunos (61\%) cursou especialização. Vale destacar que nenhum dos alunos de ambos os cursos de mestrado fez outra graduação.

As agências de fomento à pesquisa defendem o ingresso imediato do graduado no curso de mestrado tendo em vista a agilização de sua formação como pesquisador. Autores como Velloso e Velho (2001) salientam que, aqueles que procuram o mestrado logo em seguida à graduação provavelmente o fazem em decorrência de uma nítida opção pela carreira acadêmica, como professor e pesquisador. Entretanto, aqueles que se dirigem para o mestrado muito tempo após terem se graduado, provavelmente o fazem em decorrência de novas exigências relacionadas à sua atividade profissional.

\section{Análise da experiência em pesquisa na graduação}

A segunda parte do questionário referia-se a informações sobre a experiência em pesquisa na graduação por parte do mestrando. A primeira questão dessa parte indagava se ele havia tido experiência em pesquisa no decorrer da graduação.

No curso B apenas dois alunos (11\%) afirmaram não ter tido experiência em pesquisa na graduação, os outros 16 alunos $(89 \%)$ afirmaram ter tido. No curso A cinco alunos (50\%) responderam ter tido experiência em pesquisa, enquanto que os outros cinco responderam que não. Segundo Demo (2000) a experiência em pesquisa na graduação é muito importante não apenas para a formação profissional como para melhor preparar o aluno para o curso de pós-graduação. Nesse sentido o grupo do curso B apresentou maior número de alunos preparados para o trabalho da pós-graduação do que o grupo do curso A.

Quando questionados sobre o motivo de não terem tido experiência em pesquisa na graduação, os alunos do curso B não responderam à questão. Com relação aos mestrandos do curso A, quatro responderam ter sido devido a fatores institucionais, como a falta de incentivo e orientação da universidade, apenas um deles atribuiu a fatores pessoais, como falta de tempo disponível.

Em seguida, os alunos foram questionados sobre o tipo de experiência em pesquisa que haviam tido durante a graduação. Alguns deles deram mais de uma resposta a esta questão. Verificou-se que a maioria dos alunos (67\%) do curso B indicou ter participado de pesquisa científica com bolsa de estudos. Oito desses mestrandos (44\%) realizaram monografia de conclusão de curso e oito deles (44\%) relataram ter participado de pesquisas em disciplinas da graduação. Apenas um aluno (5\%) participou como voluntário em pesquisa. Dos alunos do curso A apenas um (10\%) relatou ter recebido bolsa do Programa Institucional de Bolsas de Iniciação Científica do Conselho Nacional de Desenvolvimento Científico e Tecnológico (PIBIC/CNPq), sendo que a maioria respondeu ter tido a experiência em pesquisa na graduação ao elaborar a monografia de conclusão de curso e simultaneamente participar de pesquisas como voluntários. Um último se referiu à participação em um projeto de extensão (categoria Outros). Portanto apenas um aluno desse grupo teve oportunidade de realizar a iniciação científica.

A questão seguinte estava relacionada à existência de contribuição da experiência em pesquisa na graduação para o trabalho de pesquisa na pós-graduação. Dos 10 mestrandos do curso A, apenas seis responderam a essa questão, sendo que, dos que a responderam, apenas dois (33\%) declararam que houve contribuição para o trabalho na pós-graduação, enquanto os outros quatro (67\%) responderam que não houve contribuição. Dos 18 mestrandos do curso B, quinze $(83 \%)$ responderam que houve contribuição para o trabalho na pós-graduação, um (6\%) respondeu que não houve contribuição e dois alunos (12\%) não responderam a essa questão. Portanto o grupo de alunos do curso B considerou mais positivamente a contribuição da experiência em pesquisa na graduação para sua formação de pesquisador.

Analisaram-se as respostas de ambos os grupos referentes aos tipos de contribuição que a experiência em pesquisa na graduação forneceu para o trabalho a ser desenvolvido na pós-graduação. A maioria das respostas foi dada por alunos do curso B. De acordo com $77 \%$ deles a contribuição estava relacionada com a aprendizagem das etapas metodológicas da pesquisa. Em segundo lugar surgiu a categoria relacionada à continuidade existente entre a pesquisa da graduação e a da pós-graduação (11\%) e por último a categoria relacionada a aspectos pessoais, na qual o aluno indicou que essa experiência lhe deu maior segurança em suas atividades. Apenas um aluno do curso A respondeu a essa questão indicando a aprendizagem das etapas metodológicas. Tais resultados confirmam a importância que tem sido atribuída pelas agências de fomento à experiência da iniciação científica, como preparo para a formação do pesquisador no nível de mestrado, pois ela permite que o aluno aprenda a trabalhar com as etapas da pesquisa. Os alunos do curso A pouco contribuíram para essa informação possivelmente porque tenham tido um menor número de experiências com a pesquisa científica durante a graduação.

Com relação às respostas sobre a não contribuição da experiência da pesquisa na graduação para o mestrado quatro alunos do curso A responderam, sendo que dois deles a relacionaram a fatores institucionais como o pouco tempo de 
envolvimento que tiveram com as atividades de pesquisa e, os outros dois, responderam que houve descontinuidade entre a temática de pesquisa trabalhada na graduação e aquela trabalhada na pós-graduação. Essa última também foi a resposta dada pelo único aluno do curso $\mathrm{B}$, o qual mencionou que sua experiência em pesquisa na graduação não contribuiu para o trabalho de mestrado.

A última questão desta parte do questionário referia-se a sugestões a serem dadas pelos mestrandos para melhorar a formação em pesquisa na graduação visando o trabalho a ser desenvolvido no curso de pós-graduação.

A maioria das respostas de ambos os grupos $(60 \%$ do curso A e $39 \%$ do curso B) foi relacionada ao processo ensino-aprendizagem. Nessa categoria foram apresentadas sugestões para que os professores estimulassem os alunos e demonstrassem a importância da pesquisa no desenvolvimento cientifico, a necessidade de divulgação e ampliação dos grupos de pesquisa da instituição, maior informação para os alunos sobre as pesquisas que estavam sendo desenvolvidas, além de maior incentivo e esclarecimento sobre a carreira acadêmica.

A segunda categoria que obteve mais respostas (40\% de alunos do curso A e $22 \%$ de alunos do curso B) foi relacionada a mudanças a serem realizadas nos cursos de graduação, em especial no que se refere à inserção de disciplinas nas quais fosse obrigatória a realização de pesquisas.

Apenas dois alunos do curso B (11\%) consideraram que deveria ser introduzida uma continuidade dos trabalhos de pesquisa conduzidos na graduação com aqueles realizados na pós-graduação.

\section{Análise da experiência no mestrado}

Esta última parte do questionário procurou identificar em que estágio os alunos se encontravam no que se refere às suas atividades no mestrado, como os participantes avaliavam o seu domínio sobre cada uma das etapas de realização da pesquisa e como, em sua opinião, o curso de mestrado poderia melhorar as condições para a formação do pesquisador.

A respeito do desenvolvimento das atividades do mestrado seis alunos do curso A (60\%) haviam concluído os créditos das disciplinas, e quatro deles ainda as estavam cursando. Dos dezoito alunos do curso B, dezessete responderam que tinham concluído os créditos das disciplinas, e apenas um deles não respondeu a essa questão. Considerando que as coletas de dados foram realizadas com alunos que estavam cursando o terceiro semestre do curso observa-se que vários alunos do curso A estavam atrasados em relação ao andamento de sua pesquisa na pós-graduação, uma vez que o prazo dado pelas agências de fomento para o cumprimento dos requisitos do mestrado, incluindo a defesa de dissertação, é de dois anos a partir da data de ingresso no curso, o que geralmente exige que os alunos cumpram os créditos das disciplinas nos dois primeiros semestres.

No que tange ao estágio do desenvolvimento da pesquisa, a Figura 1 mostra os resultados para ambos os grupos. Três alunos (30\%) do curso A ainda estavam na fase de elaboração do projeto de pesquisa, enquanto que todos os alunos do curso B haviam ultrapassado essa fase. Por outro lado 50\% (9) dos alunos do curso B já haviam realizado o exame de qualificação ou defendido a dissertação contra apenas um do curso A que havia se qualificado, o que evidencia um adiantamento maior dos alunos do curso B na realização do trabalho de mestrado.

As fases de coleta e análise de dados apresentaram um percentual maior de alunos do curso B e a redação da dissertação um percentual ligeiramente maior de alunos do curso A. Deve-se considerar que o trabalho sobre essas etapas pode estar ocorrendo concomitantemente entre si e com a qualificação.

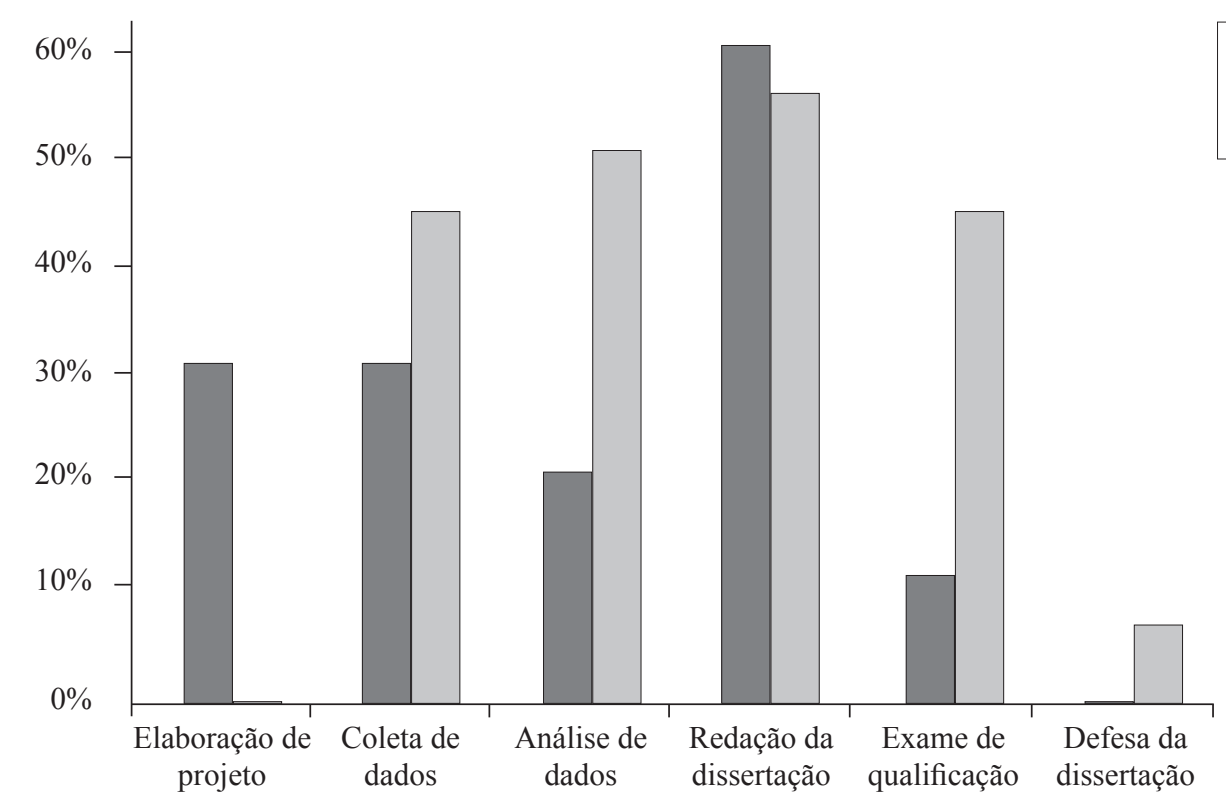

Curso A - \%

Curso B - \%

Figura 1. Estágio em que se encontra o desenvolvimento da pesquisa. 
Nessa parte do questionário havia também uma questão que solicitava aos mestrandos que avaliassem seu domínio sobre cada uma das etapas de realização de pesquisa, a partir de uma escala de cinco pontos que variava de Ruim a Excelente. Havia também uma opção "Não trabalhou" para o caso do mestrando ainda não ter atuado em relação a uma determinada etapa. Na Figura 2 encontram-se as respostas relacionadas à avaliação de seu domínio das etapas de planejamento da pesquisa dos alunos do curso A. Na Figura 3 estão as respostas desse mesmo grupo relacionadas às etapas de execução da pesquisa.

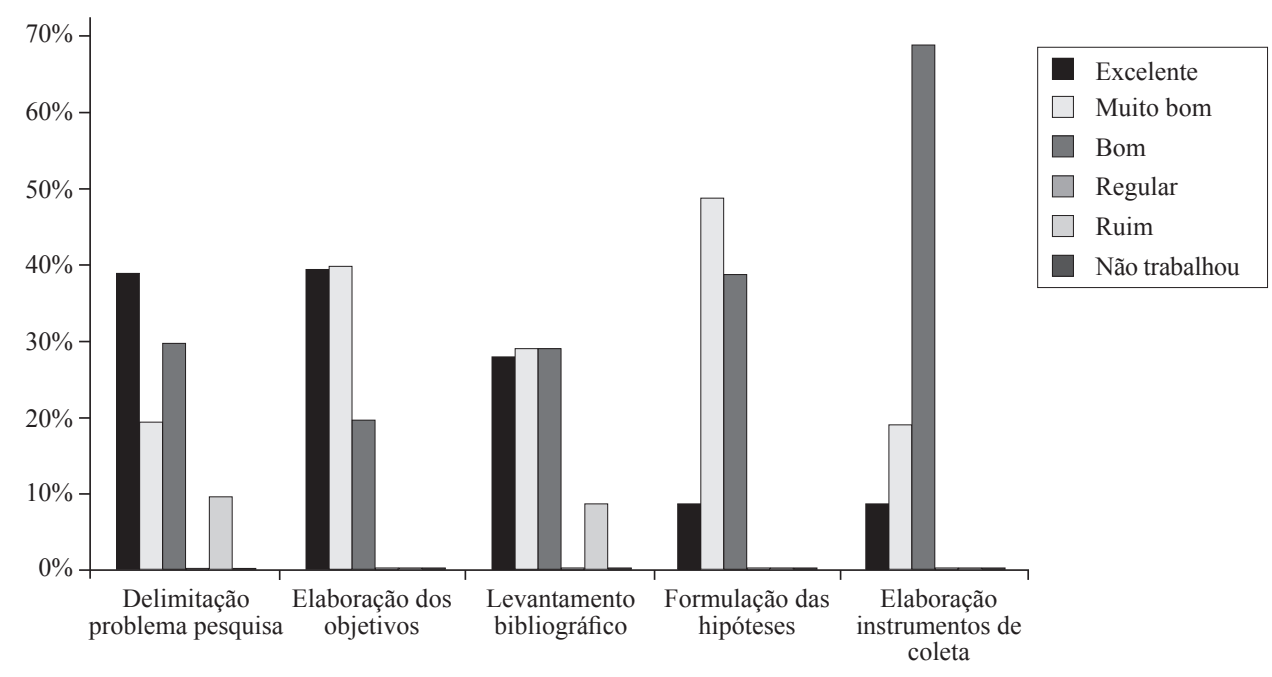

Figura 2. Avaliação do domínio das etapas de planejamento da pesquisa pelos alunos do curso A.

A Figura 2 mostra que a maioria das respostas dos alunos foi para as categorias "Excelente" e "Muito Bom" em relação a todas as etapas de planejamento de pesquisa à exceção da etapa de Elaboração dos instrumentos de coleta de dados para a qual a maioria das respostas $(70 \%)$ foi para a categoria "Bom". Tais resultados indicam que a elaboração dos instrumentos teve uma dificuldade maior para esses alunos, uma vez que a categoria "Bom" representava o ponto médio da escala de avaliação. Houve também 10\% de respostas para a categoria "Ruim" em relação às etapas de Delimitação do problema de pesquisa e de Levantamento Bibliográfico, indicando que para uma minoria de alunos houve dificuldades não superadas até o momento da avaliação em relação a essas etapas.

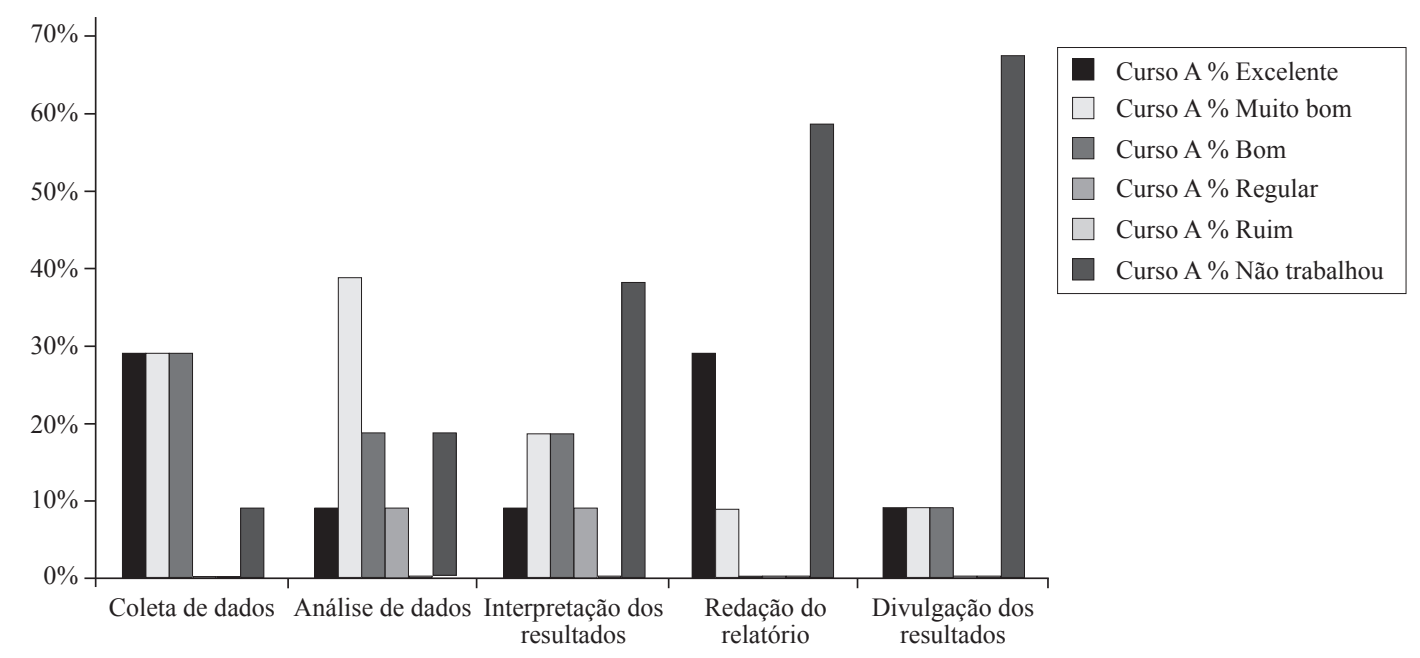

Figura 3. Avaliação do domínio das etapas de execução da pesquisa pelos alunos do curso A.

A Figura 3 mostra que houve melhor avaliação de domínio para as etapas de Coleta e Análise de dados nas quais a porcentagem de respostas nas categorias "Excelente" e "Muito Bom" foi maior ou igual à obtida pelas demais categorias. As etapas Análise de dados e Interpretação dos resultados apresentaram cada uma $10 \%$ de respostas na categoria "Regular". Observa-se uma porcentagem crescente de respostas para a categoria "Não trabalhou" em relação às etapas finais de realização da pesquisa. A etapa de Redação do relatório embora tenha tido avaliação superior por $40 \%$ 
dos alunos (categorias "Muito Bom" e "Excelente") teve indicação por $60 \%$ deles de que não haviam trabalhado sobre a mesma. Tais resultados estão coerentes com aqueles relacionados ao atraso em relação ao andamento do trabalho do mestrado para esse grupo, descrito anteriormente (Figura 1). Deve-se também ressaltar que um número significativo de alunos (70\%) não havia se envolvido com a Divulgação dos resultados da pesquisa, o que já deveria ter ocorrido no segundo ano do curso de mestrado.

A Figura 4, referente à avaliação de domínio das etapas de planejamento da pesquisa pelos alunos do curso B, mostra que houve um predomínio $(50 \%$ ou mais de respostas) de avaliações na categoria "Bom" para as etapas Delimitação do problema de pesquisa, Formulação de hipóteses e Elaboração dos instrumentos para as coletas dos dados. Para a etapa Elaboração dos objetivos houve predomínio de respostas $(55 \%)$ para as categorias de avaliação superior (Muito bom e Excelente). A etapa de Formulação das hipóteses foi a que teve menor porcentagem de respostas (22\%) nessas categorias, além de um aluno ter assinalado que não trabalhou sobre a mesma. Todas as etapas apresentaram respostas na categoria "Regular".

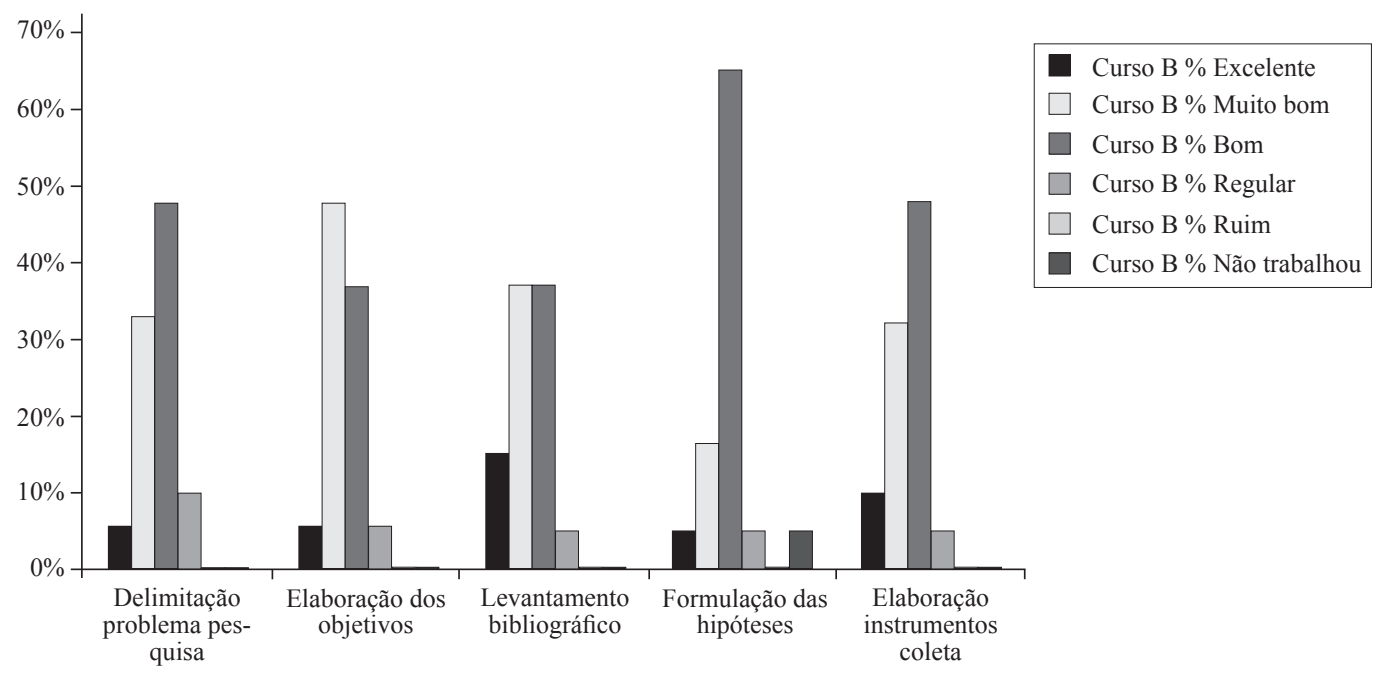

Figura 4. Avaliação do domínio das etapas de planejamento da pesquisa pelos alunos do curso B.

A Figura 5, também contendo resultados dos alunos do curso $\mathrm{B}$, referentes à avaliação de domínio sobre as etapas de execução da pesquisa, mostra que houve predomínio de avaliações na categoria "Bom" para todas as etapas de execução da pesquisa à exceção da Coleta dos dados, para a qual as respostas nas categorias "Muito Bom" e "Excelente" somaram 56\%. Todas as etapas receberam avaliações na categoria
“Regular" à exceção da Coleta dos dados. Todas também tiveram respostas na categoria "Não trabalhou", cujo percentual aumentou em relação às etapas finais da pesquisa, chegando a $22 \%$ para a Divulgação dos resultados, percentual bem menor do que o apresentado pelo grupo do curso A. Tais resultados, portanto, estão coerentes com o estágio de adiantamento do trabalho de pesquisa dos alunos do curso B (Figura 1).

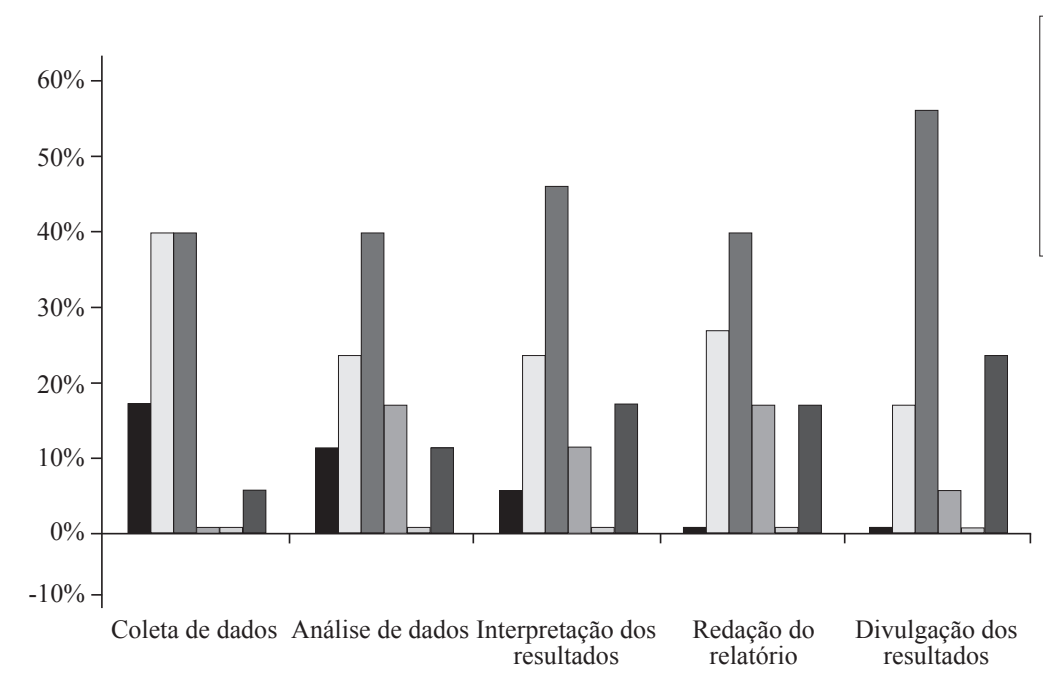

Figura 5. Avaliação do domínio das etapas de execução da pesquisa pelos alunos do curso B. 
Também foi perguntado a esses alunos se teriam sugestões para melhorar a formação do pesquisador no decorrer do mestrado. A maioria das respostas de ambos os grupos ( $50 \%$ do curso A e 39\% do curso B) foi para a categoria $\mathrm{Mu}-$ dança no curso, na qual foram encontradas sugestões do tipo "mais oferta de disciplinas", "aumentar os créditos", "alterações nas disciplinas e em atividades de seminários que poderiam ser agregadas à grade curricular". Em seguida com o mesmo número de respostas em ambos os grupos vieram as categorias Processo ensino/aprendizagem e Condições materiais. Em relação ao processo ensino/aprendizagem houve sugestões tais como "realização de eventos nos quais os mestrandos possam apresentar seus trabalhos" e "grupos de pesquisa mais acessíveis aos alunos". Na categoria condições materiais foram sugeridas "ampliação da biblioteca" e "melhoria nos laboratórios".

Esses resultados mostram a importância atribuída pelos alunos aos aspectos estruturais e de funcionamento dos cursos que, segundo eles, precisam ser discutidos e alterados para que a formação do pesquisador, durante o mestrado, seja melhorada. Os resultados sinalizam também para a necessidade de atentar para o desenvolvimento da relação entre professor e aluno, além de promover investimentos materiais.

\section{Considerações finais}

Considerando a importância da produção de conhecimentos para a resolução de problemas das comunidades regional e nacional tornam-se necessárias a análise e avaliação do processo de formação de pesquisadores, visando sistematizar suas características e sinalizar sugestões para sua melhoria. Cabe, então, destacar os principais aspectos dos resultados obtidos com esse dois grupos estudados.

O grupo do curso B apresentou características mais aproximadas aos parâmetros propostos pelas agências de fomento para a formação do pesquisador, ou seja, média de idade mais baixa (27,2 anos) e menor tempo médio despendido entre o término da graduação e o início da pós-graduação (3,6 anos) que o grupo do curso A. O estudo de Weber (2003) comparando os cursos de mestrado em Psicologia de diferentes regiões do país, mostra que os egressos concluíram o mestrado com média de idade de 30 anos e maior tempo (média de 6 anos) transcorrido entre a graduação e a pósgraduação. Os resultados dessa pesquisa são semelhantes aos que foram encontrados no grupo do curso A. Portanto, em nosso país, a realidade de cursos de pós-graduação nessa área ainda não está equiparada aos objetivos das agências quanto a esses aspectos.

Em relação à dedicação ao mestrado os alunos do curso B apresentaram melhores condições para a dedicação exclusiva, pois $67 \%$ deles contavam com bolsa de estudos, enquanto que apenas $10 \%$ dos alunos do curso A tinham bolsa. De acordo com Velloso e Velho (2001) a condição de trabalho no mestrado tem repercussões sobre o tempo para o término do mesmo. Deve-se aqui salientar que esses autores também encontraram maior distribuição de bolsas de estudos entre cursos da região sudeste do que da região nordeste. Tal fato pode estar relacionado à maior consolidação da pós-graduação na região sudeste, que apresenta cursos credenciados há mais tempo junto à CAPES e com melhor avaliação, à qual está atrelada a concessão das bolsas de estudos. Outro aspecto a ser destacado é que o curso B pode contar com bolsas de uma fundação estadual já consolidada, enquanto que a fundação estadual à qual o curso A pode recorrer ainda se encontra em processo de consolidação.

Com relação à formação em pesquisa na graduação os alunos do curso B também apresentaram condições mais favoráveis do que os do curso A, pois $67 \%$ deles haviam tido a experiência de iniciação cientifica contra $10 \%$ dos alunos do outro curso. Tal formação aliada à condição de dedicação ao mestrado pode explicar o cumprimento das etapas da pesquisa de forma mais adequada ao tempo apresentado pelos alunos do curso B, quando se considera a exigência da CAPES de que as atividades do mestrado, incluindo a defesa de dissertação, se encerrem no período de dois anos.

A respeito da avaliação do domínio das etapas de pesquisa o grupo do curso B apresentou maior percentual de respostas na categoria "Bom" para um maior número de etapas de planejamento e de execução da pesquisa do que o grupo do curso A. Os alunos deste último curso, por sua vez, apresentaram, para várias das etapas, maior percentual de respostas nas categorias "Muito Bom" ou "Excelente". Tais resultados indicam no geral avaliação menos positiva de seu domínio pelo grupo do curso B.

O percentual de alunos do curso A que indicou não ter trabalhado em etapas de execução da pesquisa, principalmente as finais, foi muito maior do que o dos alunos do curso B, o que pode indicar riscos de que a finalização de seus trabalhos supere os prazos aos quais os cursos devem se adequar.

As respostas de avaliação na categoria "Regular" que, embora em baixo percentual, surgiram em quase todas as etapas de realização de pesquisa de ambos os grupos revelam inseguranças e insatisfações do mestrando com relação à sua aprendizagem na realização de pesquisa, objetivo central da formação oferecida pelo curso de mestrado.

O instrumento de coleta de dados não levantou as razões para as avaliações de domínio das etapas de pesquisa realizadas pelos mestrandos, mas os resultados indicaram alguns aspectos que poderiam orientar as discussões entre alunos e coordenações de curso. Dentre eles sugere-se o enfoque das razões que levaram às avaliações de domínio na categoria "Regular", o levantamento de fatores que estariam influindo para o mestrando não ter trabalhado com algumas das etapas da pesquisa, e as implicações dos atrasos para o término do trabalho e para a aprendizagem das diferentes etapas de realização da pesquisa. Também é sugerido discutir se as avaliações de domínio na categoria "Bom" poderiam ser melhoradas no decorrer do trabalho no curso e mediante quais condições. O levantamento dessas razões também seria importante para indicar quais fatores estão relacionados às 
diferentes categorias de avaliação, tais como, aqueles relacionados ao funcionamento do curso, ao processo de orientação, à situação pessoal do mestrando.

Com relação às sugestões para melhorar a formação do pesquisador na graduação observou-se, nas respostas dos mestrandos, a atribuição da responsabilidade ao professor, pois para ambos os grupos a maioria das respostas esteve relacionada a este aspecto (categoria processo ensino-aprendizagem). Para a formação no mestrado, as sugestões mais frequentes foram aquelas relacionadas às alterações no funcionamento do curso (categoria Mudança no curso). Tais sugestões também deveriam ser discutidas entre coordenações e alunos.

Esta pesquisa buscou contribuir para o conhecimento do processo de formação em pesquisa sob a perspectiva do próprio sujeito do processo: o aluno do curso de mestrado. Também contribuiu para a obtenção de indicadores sistematizados que possam ser utilizados para a melhoria do processo de formação do pesquisador. Os resultados obtidos sinalizaram para alguns pontos de dificuldades, e também para aspectos positivos da formação que deveriam ser pesquisados em outros cursos para verificar sua regularidade de ocorrência. Sugere-se também o aperfeiçoamento do instrumento de coleta de dados de forma a incluir informações que possam esclarecer e aprofundar a análise que o mestrando faz de sua própria formação.

\section{Referências}

Bardin, L. (2004). Análise de conteúdo (3a ed.). Lisboa: Edições 70.

Dal Ri, N. M. (1996). Iniciação científica: Desenvolvimento e avaliação. Anais do Encontro de Orientadores e Orientandos de Iniciação Científica, 1, 29-38.

Demo, P. (2000) Educar pela pesquisa.São Paulo: Autores Associados.

Fávero, M.L.A. (1998). A produção científica sobre educação superior: anotações para um debate. In: M. Morosini \& V. Sguissardi (Orgs.), A educação superior em periódicos nacionais (pp. 35-43). Vitória: Ed. UFES.

Gil, A. C. (1999). Métodos e técnicas de pesquisa social (5a ed.). São Paulo: Atlas.

Gomes, C. R. (2004). Análise da formação em pesquisa oferecida pela universidade. Relatório final apresentado à Comissão do PIBIC. São Cristovão, SE: UFS.

Lei No. 9.394, de 20 de dezembro de 1996. (1996, 23 de dezembro). Estabelece as Diretrizes e Bases da Educação Nacional. Diário Oficial da União, seção 1.

Leite, S. A. S. (1996). Desafios para a pesquisa em iniciação científica. In E. M. Bomfim (Org.), Formações em psicologia: Pós-graduação e graduação (pp. 117-127). Belo Horizonte: UFMG/ANPEPP.

Machado, L. M. M. (1996). Avaliação da iniciação científica. In E. M. Bomfim (Org.), Formações em psicologia: Pósgraduação e graduação (pp. 97-101). Belo Horizonte: UFMG/ANPEPP.
Neves, C. E. B. (2002). A estrutura e o funcionamento do ensino superior no Brasil. In M. S. A. Soares (Org.), Educação superior no Brasil (pp. 43-86). Brasília, DF: CAPES.

Olive, A. C. (2002). Histórico da educação superior no Brasil. In M. S. A. Soares (Org.), Educação superior no Brasil (pp. 31-42). Brasília, DF: CAPES.

Paiva, N. (2001). Iniciação científica. Belo Horizonte: Centro Universitário Newton Paiva.

Pardo, M. B. L. (2004a). Análise da formação em pesquisa oferecida pela universidade. Projeto de pesquisa apresentado ao PIBIC/CNPq/UFS. São Cristóvão, SE: UFS.

Pardo, M. B. L. (2004b). Análise da formação em pesquisa oferecida pela universidade. Relatório Final de Atividades apresentado à FAP-SE. São Cristóvão, SE: UFS.

Perez, J. F. (2002). Pesquisa: A construção de novos paradigmas. São Paulo em Perspectiva, 16(4), 30-35.

Santos, M.(2005). Análise da formação em pesquisa oferecida pela universidade. Relatório parcial apresentado à Comissão do PIBIC/CNPq/UFS. São Cristóvão, SE: UFS.

Simão, L. M. (1996). A iniciação científica enquanto processo de construção de conhecimento: Um enfoque para reflexão. In E. M. Bomfim (Org.), Formações em psicologia: Pós-graduação e graduação (pp. 89-95). Belo Horizonte: UFMG/ANPEPP.

Velloso J. (Org.). (2003). A pós-graduação no Brasil: Formação e trabalho de mestres e doutores no país (pp. 29-31). Brasília, DF: CAPES.

Velloso, J., \& Velho, L. (2001). Mestrandos e doutorandos no país. Trajetórias de formação. Brasília, DF: CAPES.

Weber, S. (2003). Psicologia: Mestres e doutores titulados entre 1990 e 1999. In J. Velloso (Org), A pós-graduação no Brasil: Formação e trabalho de mestre e doutores no país (Vol. 2, pp. 221-243). Brasília, DF: CAPES.

Maria Benedita Lima Pardo é Professora Associada do Departamento de Psicologia da Universidade Federal de Sergipe. Neucideia Aparecida Silva Colnago é Pesquisadora visitante do Instituto de Estudos Avançados da Universidade de São Paulo, campus São Carlos-SP.
Recebido: 03/09/2009

$1^{a}$ revisão: $29 / 05 / 2010$

Aceite final: 25/11/2010 